\title{
CREACIÓN Y MEMORIA
}

\author{
Gerardo DIEGO / José GARCÍA NIETO \\ Edición de Francisco DÍEZ DE REVENGA
}

(Barcelona: Anthropos / Fundación Gerardo Diego /

Fundación José García Nieto, 2014, 142 págs.)

Con motivo de cumplirse el pasado año el centenario del nacimiento de José García Nieto (Oviedo, 1914 - Madrid, 2001), uno de los poetas más destacados del panorama literario español de posguerra, el profesor Francisco Javier Díez de Revenga, catedrático de Literatura Española de la Universidad de Murcia, profundo conocedor de este escritor y reconocido especialista en la Generación del 27, ha publicado en la prestigiosa editorial Anthropos, su libro Creación y memoria. En él nos ofrece, a través de una serie de textos inéditos y otros de no fácil localización, el testimonio de la profunda amistad que este escritor sostuvo con el poeta Gerardo Diego, a quien siempre consideró como su maestro.

Dicha selección va precedida de un interesante estudio introductorio en el que Díez de Revenga realiza una semblanza de José García Nieto, lamentando el olvido en que ha caído este extraordinario poeta, subrayando la importancia de su obra lírica, desde su primer poemario Víspera hacia ti (1940) hasta la publicación del volumen Poesía (1996) que recogía una importante selección de su obra. Pero además, Díez de Revenga resalta el papel destacadísimo que tuvo García Nieto en los momentos difíciles de la Posguerra, dando cabida en su revista Garcilaso a todos los poetas sin fijarse en su adscripción ideológica, y manteniendo una presencia constante en encuentros y reuniones, siempre dispuesto a ayudar a los demás.

Tras destacar las afinidades existentes en la obra de ambos escritores: "García Nieto es el poeta "garcilasista" y "neoclásico", emparentado con la mejor poesía del siglo XX, fundamentalmente con Gerardo Diego, y, a lo largo de sus más de treinta libros poéticos, hay que confirmar, con el neoclasicismo, iniciativas y multiplicidades muy innovadoras", Díez de Revenga lleva a cabo un comentario pormenorizado de cada uno de los textos que nos ofrece en su libro, en donde con rigor y amenidad expresa su significado y trascendencia. Su profundo conocimiento de la obra de ambos poetas y del panorama literario español del siglo XX le permite moverse como pez en el agua a la hora de seleccionar, valorar y comentar este conjunto de escritos -dispersos y olvidados entre las página de las distintas publicaciones en que aparecieron- que uno a otro se dedicaron y que, sin duda, contribuyen a un mejor conocimiento de sus vidas y de sus obras. 
Creación y memoria recoge diversos artículos y pequeños ensayos que Díez de Revenga agrupa en dos grandes apartados: “Gerardo Diego sobre José García Nieto” y, viceversa, "José García Nieto sobre Gerardo Diego". A través de su lectura descubrimos la siempre respetuosa relación maestro-discípulo que ambos mantuvieron durante más de 30 años, rebosante de afecto y de admiración mutua, en dos escritores caracterizados por su bondad, sencillez y sentido de la amistad. $Y$ todo ello inmerso en el marco del panorama literario español de la posguerra, donde Gerardo Diego -fiel seguidor de las revistas literarias surgidas en los años veinte y treinta, imposible olvidar sus Carmen y Lolaalaba ahora al joven creador de la revista Garcilaso en cuyas páginas él mismo colaboró, junto a otros poetas de su generación como Vicente Aleixandre o Dámaso Alonso.

Las palabras siempre elogiosas del maestro para su discípulo: "García Nieto es un poeta perfecto", se suceden desde la publicación de su primer libro Víspera hacia ti, y siguen luego con Tregua -en el que destaca la maestría en el uso del soneto-, Memorias y compromisos y, finalmente, Taller de arte menor y cincuenta sonetos, poemarios en los que valora sustancialmente el personalismo de su poesía, frente a las reminiscencias clásicas que aquel pudiera tener. Además, Gerardo Diego no pierde ocasión para felicitar públicamente a García Nieto por los diversos premios literarios que va consiguiendo: el Premio Nacional de Literatura Garcilaso o el Fastenrath, por su libro La red, premios que considera merecidísimos y que supusieron importantes hitos en la paulatina consolidación de su carrera literaria.

En justa reciprocidad, encontramos en los 17 textos que García Nieto escribe sobre Gerardo Diego, la admiración del poeta más joven por el venerado autor de Alondra de verdad, ya alegrándose de su entrada en la Real Academia Española, ya glosando el éxito de una lectura poética de su libro de ambiente taurino La suerte o la muerte en el Instituto de Cultura Hispánica, o bien desvelando retazos más íntimos de su carácter al hablar de la impavidez y de la sempiterna timidez que el gran poeta del 27 no se esforzaba en ocultar: "Yo soy un tímido y se me nota", cuenta que le había confesado en alguna ocasión.

Destaca también García Nieto en estos textos aquí recogidos, otros aspectos que muestran la bondad de Gerardo Diego, su generosidad y altura de miras, a la hora de expresar, sin ápice de rencor alguno, su admiración por la alta calidad de la lírica de Neruda, pese a que el poeta chileno le ofendiera gravemente en su Canto General: "Que sepan los malditos (...), los Dámasos, los Gerardos, los hijos de perra, silenciosos cómplices del verdugo." García Nieto, buen amigo y atento seguidor de la trayectoria vital y artística de su maestro, va dejando memoria de los logros de su carrera: la concesión de la Medalla del Trabajo (1968), el Doctorado Honoris Causa por la Universidad de Santander (1980), el Premio Cervantes (1979), la edición de Clásicos Castalia de Alondra de verdad y Ángeles de Compostela (1988), para terminar este acompañamiento con un emocionado discurso que leyó en la Real Academia a la muerte del poeta en 1987. 
Tras los textos, se recogen 8 cartas de Gerardo Diego a García Nieto y 16 que este último dirige a aquel. Interesante epistolario que además de manifestar la excelente relación que ambos poetas tuvieron, pone de manifiesto la siempre atenta y eficaz colaboración que el poeta más joven prestó al mayor en cuantas gestiones éste le requería.

Finalmente, de los archivos de las familias de ambos poetas, Díez de Revenga selecciona algunos poemas dedicados, que dan fe de la mutua simpatía y confianza que uno y otro se dispensaron.

Creación y memoria supone una valiosa y oportuna aportación para un mejor conocimiento de la relación entre estas dos grandes figuras del panorama literario español del siglo XX, que compartieron por igual, de forma merecida, la gloria del Premio Cervantes, unidas por una inquebrantable amistad y admiración mutuas.

Manuel Llanos de los Reyes 